\title{
On the Impact Factors for Mining Enterprise Choosing Investment Position Abroad
}

\author{
Maoping Zhou \\ Jiangxi University of Science and Technology, \\ Ganzhou ,China \\ Email: zmpxmz@163.com
}

\author{
Mingzhen Xu \\ College of Applied Science,Jiangxi University of \\ Science and Technology, Ganzhou ,China \\ Email: xmzxmz1972@163.com
}

\begin{abstract}
Mining enterprise investment is characteristic of long period, big size and fixed area. Resource, polity, law, economy environment and social culture of the host country should be taken into account when choosing place for offshore fund.
\end{abstract}

Keywords-mining enterprise; overseas investment;location choice; impact factor

\section{Introduction}

The prime aim of investing mining abroad by mining enterprise is to solve home mine resource gap and to make sure the sufficient mine supply for the steady development of national economy. Another important aim consist of helping Chinese mining enterprise participate into efficient collocation of global mine resource to break up the international mining monopolizing by few mining enterprises of developed countries so that home mining enterprises may take an important place in the international market. However, any industry or enterprise will run big risks for their management activity abroad. The way and size of investment is based on confirming the offshore fund location because of the different investment surroundings in different investment area. The different investment surroundings will influence the detailed management activity by enterprises. Therefore, we will analyze the essential problem related with investment location choice from the broad point of view in detail.

\section{Resource Gift Factor}

Resource gift refers to the basic material condition and the investment condition in management activity of enterprises. As far as the current economy system and the market system are concerned, resource gift not only includes the traditional production factors such as the natural resource and labor force resource but also the modern production factors such as the capital resource, technology resource, industry system, information and management . Resource gift is one of the essential conditions in the place decision which is formed by nature and nurture. Different country or area is different in the enrichment of resources, which is one of the most important factors in decision-making for the resource-led investment.

\section{A Nature Resource}

When mining enterprise makes investment decision, the prior factor mining enterprise should consider is the nature resource. The quality of nature resource in the host country is the most basic factor considered by resource-led enterprises because they aim to fill domestic mine resource gap as possible as they can. The global copper resource distribution, for instance, is mainly in South America, USA, Poland, Australia, Russia, Zambia, the Democratic Republic of Congo, Kazakhstan and Canada. Therefore, the copper enterprises should base their overseas investment on these countries. When considering the enrichment of the nature resource, these enterprises also should take the quality of resource into account. Because low ore grade not only makes the ore exploration and beneficiation much difficult, but also makes higher project cost for exploiting ore, and then cause losses to the investment.

\section{B Labor Force Resource}

Labor force resource of the country is also one of the important factors in the process of investment position decision-making because labor cost is relatively important among many production cost factors. Labor cost reflects the labor resource gift, the labor supply and its price so that labor cost have direct influence on the economic benefit of investment. Many transnational corporations in America and Japan take labor cost and skilled labor supply as one of the important factors. Particularly, the labor-led enterprises often choose those countries which are rich in labor resource and low labor cost to invest.

\section{Science and Technology Resource}

In recent years, more and more enterprises tend to invest in some regions with advanced science or technology in order to make full use of intellectual capital and skill spillover effect of the host country and to gain the advanced technology and experience needed for their own. China has made project decision in the way of analogy and experience when exploiting mining. Mining has been considered as a skill but not a science in China which is the main reason for the big gap between international mining enterprises and Chinese mining enterprises. Only relying on advancement of technology can Chinese mining enterprises deal with the key technical problem better. Therefore, the main investor should focus on science and technology resource of the host country, studying and learning from it, to make the investment project proceed smoothly.

\section{Political and Legal Factors}

Political and legal factors refer to the host country's political system and the system of laws and regulations. As the superstructure of the state, they have great influence on the economic basis, and they are the significant external factors which need to be assessed when enterprises of any 
kind want to make strategic policy of investment. Mining enterprises are no exception.

\section{A}

\section{Political Stability}

Generally speaking, the national political stability is the basic condition to ensure economic development of a country. A region of high political stability tends to attract long-term constructive investment of foreign investors. In contrast, it is quite difficult for a region of low political stability to gain investors' favor.

Since the mining industry has characteristics of long investment cycle, large investment scale and inflexible producing location, enterprises have to make long-term preparation to face all kinds of risks.

If the political situation of a country often shows signs of unstableness, definitely it is extremely disadvantageous to the mining enterprises. In Africa, not only are the kinds of mineral resources a lot, but also the reserves are rich, so it is known as "raw materials storehouse of the world". However, because of the factors of history, religion, colonial rule, races, etc in the African continent, wars and violent conflicts frequently occur in many countries. They terribly influence the investment of mining industry. As a result, investors are especially cautious to African countries when choosing investing region.

\section{B The Functions and Attitude of the Government}

The regeneration of mineral resources makes the country of rapid-developing industry and economy faced with the dependence on the external supply of mineral resource. Therefore, the so-called "strategic minerals" and "scarce minerals" emerge. Under some circumstances, these fundamental mineral resources cause the fragileness of the national defense system and the economic system due to the cut of supply. In other word, mineral resources supply is to some certain extent related to the national security ${ }^{[1]}$. In this situation, the government's functional performing strength and its attitude to foreign investors is especially important.

\section{Legal System of the Country}

Legal environment's impacts on the overseas investment of enterprises include completeness, impartiality and the stability of the legal system.

First of all, as the national situation is different in various countries, the policies and provisions on foreign investment are also different, so legislation form and legislation content of the country will also be different. If investors didn't do thorough research, they would likely violate the law of the host nation.

Secondly, it would be unavoidable to have some dispute with the host country's institutions or the enterprise when a country makes direct investment abroad. Then the legal justice of the host country will directly affect the interests of investors.

Lastly, investing activity generally has a long investment cycle. If legislation of a nation changes frequently and the rules of law are not stable enough, the investors will certainly be in increasing risk ${ }^{[2]}$.

Considering the national legal factors, undoubtedly the mining enterprise should focus on the law of mining industry and the law of foreign investment. Nowadays, many countries of rich mineral resources, in order to turn the resource advantages into economic benefit, try to attract foreign investment by continuously improving and modifying the relevant legislation on mining investment. Most developed industrialized nations have a mature whole set of mining legal system. Comparing to the former, some developingcountries of lower comprehensive national power still have defects in legislation.

Therefore, when choosing investment location, the mining enterprise should pay close attention to the relevant laws and regulations on mining industry of the host country and study carefully, so as to reduce the legal risk of overseas investment.

\section{Economic Factors}

From macro perspectives, economic factors are the general conditions under which a nation engages in investments and manufacturing management activities and the most important factors that affect overseas investment and location. According to the historical statistics of UNCTAD, two-thirds of the direct investments flow to the developed countries in the world. Because they have a larger economy scale and enormous potential market and high regional integration. As the essential system in the investment environment, economic level, economic stability and opening-up level are included in.

\section{A Economic Level}

Generally speaking, foreign direct investment is very closely linked to economic performance. They interact as both cause and effect. Economic growth will increase the foreign direct investment and promote more foreign capital inflow. The grade of foreign direct investment will also improve the economic level of a country to some degree ${ }^{[3]}$.

Mining industry is affected by the economic level in the following two aspects: First, low economic level leads to poor mining such as backward working level, technical equipment, management level and economic benefits etc. Second, mining is capital-intensive, therefore, a large amount of fund has to be poured into in the investment. And production activities will be badly affected without enough money.

\section{B Economic Stability}

Economic Stability typically means achieving full employment, stabilizing market price and balancing international payment. It includes some stable and continuous economic policies. In order to keep stable economy, we should control economic continuity in time sequence and increasing balance point in economic structure. Mining investments take more economic risks than other industries. For example, the world crisis in 2008 resulted in the change of financial market exchange rate, especially the tremendous economic impact in mining industry. Accordingly, economic stability plays a striking role in investment location of the mining enterprises.

\section{Economic Opening-up Level}

As a unique industry, mining faces more difficulties in overseas investment. Mineral resources are a great asset in a sovereign nation. They play a decisive role in country 
development due to their non-renewability. Many nations take protective measures against mining industry in order to defend their own economic interests. Meanwhile a few countries with rich mineral resources and a sparse population will maintain a high opening-up level to convert resource advantages into economic benefits by foreign capital. In which case, mining investors should be concerned about the opening-up level of the target country in investment location so that businesses may go into the country smoothly.

\section{Social Factors}

Social Factors mainly refer to the fundamental conditions of the host countries in social and cultural environment. They contain social order and structure, population quality, domestic infrastructure projects, national language, religious belief, mood of the country and social customs and habits etc. Social environment will affect the investment location of foreign investors directly and indirectly. Because various historical and development conditions result in great differences in overall national strength and cultural background, causing differences in nation building, values and mode of thinking. Investors always choose the countries which have good infrastructures and tiny differences from mother country in language to make successful investments. The article will analyze the effect of investment location from social factors in the infrastructures and cultural differences of host countries.

\section{A Infrastructure}

Mines productive activities are usually under way in the mountain or remote areas, which requires host countries to provide more sophisticated infrastructure, especially in transportation and energy supply because these factors can ensure the mines projects to go on smoothly to some degree. Taking South Africa as an example, the most concerned for investors is its poor infrastructure. But investors are very worried about the local social environment and transport costs in spite of other ventures. Many mines are far away from coastal terminals and railway construction is under poor condition so that in peak season local mine owners fight hard for railway transportation, which brings adverse effects for every investor.
Language culture is equally important to any kind of investment enterprise. Due to various languages and social cultures, there are different psychological distances among investors. Language plays an important role in communication as a tool. Many investors tend to make investments in the area which has similar geographical features and language culture backgrounds. Then we will make a brief analysis of this phenomenon.

First, people with strong senses of cultural identity have the similar social consciousness, social customs and life values with people in the investors' mother country. Investors can recruit workers by comparing and evaluating some characteristics depending on mother country's work force to reduce risks in unbalanced employment market. Second, government departments have the similar work style because of the similar social consciousness. Investors have to abide by the process and invest in the country with cultural identity so that they can form rational expectation in the operation process, rules, and unwritten rules and reduce transaction costs. Last, apart from economic reasons, culture itself, as an important factor of national identity and international communication, can promote economic integration. As an aspect of economic interchange, transnational investment is liable to develop with cultural exchange $^{[4]}$.

\section{References}

[1] Jiaqu Wang, Xiaofeng Zhang, Mining Resource and National Security[M].Beijing : Geological Publishing House, 2000. vol. 2, 102 103

[2] Xin Lv, On the Location choice in the Association of Southeast Asian Nations [D].Shandong : Qingdao University of Science and Technology , Master's Thesis, 2010,

[3] San Liu, A Quantitative Analysis On the Relationship Between Foreign Direct Investment of foreign tradesman and economic growth [J].China Business Circles, 2010, 6（1） : 101 102

[4] Guoda Gu, Zhengrong Zhang, The Function of Cultural Identity in foreign enterprise investing directly [J].Zhejiang Social Science 2007, 1 (1) : 16 21 